\title{
Potential Risk of Benzene in Petroleum-Derived Products Used from 1974 to 2012 in Korea
}

\author{
Sangjun Choi ${ }^{*}$, Sugyeong Kwak ${ }^{1}$, Donguk Park², Jee Yeon Jeong ${ }^{3}$ \\ ${ }^{1}$ Department of Occupational Health, Daegu Catholic University, Gyeonsangbukdo 38430, Korea \\ ${ }^{2}$ Department of Environmental Health, Korea National Open University, Seoul 03087, Korea \\ ${ }^{3}$ Department of Occupational and Environmental Health, Yongin University, Yongin 17092, Korea
}

\begin{abstract}
This study was conducted to assess the levels of benzene in petroleum-derived products (PDPs) through literature reviews reported in Korea and to estimate the inhalable benzene to which workers who handle PDPs containing trace amounts of benzene are exposed. All of the available data until 2012 on benzene-containing products in Korea were collected from prior studies, reports, and epidemiological surveys. A total of 32 products from 7 reagents, including ethylbenzene and trichloroethylene, were also analyzed using a gas chromatograph equipped with a mass spectrometer to confirm the trace levels of benzene. Finally, a total of 112 data sets with 131 bulk samples for benzene content information were collected. Thinner had the highest benzene content (56.7\% in 1997), followed by printing agent (30.1\% in 2005), solvent used in the maintenance and repair of motor vehicles (8.96\% in 2005), and gasoline (6.0\% in 2002). The amount of benzene contained in the PDPs exhibited a declining trend over the years, but workers handling thinners containing less than $0.1 \%$ benzene were found to be exposed to concentrations above $1 \mathrm{ppm} .13$ of the 32 reagents were also confirmed to contain benzene, and the products of trichlorethylene and ethylbenzene contained more than $0.1 \%$ benzene. In conclusion, if there is a possibility of benzene exposure, even when the benzene content is below $0.1 \%$, specifying the presence of benzene in the material safety data sheet to ensure the protection of workers is warranted.
\end{abstract}

Keywords: Benzene; Petroleum-derived product; MSDS; Reagent.

\section{INTRODUCTION}

Benzene is a natural ingredient of crude oil and therefore has been used in various chemical products derived from petroleum; it is used as an ingredient of printing ink, organic solvent, raw material and intermediate in diverse pharmaceutical and chemical industries (e.g., rubber, lubricating oil, dye, detergent, pesticide manufacturing) and an additive in unleaded gasoline (ATSDR, 2007; Williams et al., 2008).

The International Agency for Research on Cancer (IARC) classified benzene as carcinogenic to humans (Group 1) and reported that there is sufficient evidence of benzene's carcinogenicity in acute myeloid leukemia (AML) and acute non-lymphocytic leukemia (ANLL), and a positive association in acute lymphocytic leukemia (ALL), chronic lymphocytic leukemia (CLL), multiple myeloma and nonHodgkin lymphoma (IARC, 2012). In line with recognition

\footnotetext{
* Corresponding author.

Tel.: 82-53-850-3738; Fax: 82-53-850-3736

E-mail address: junilane@gmail.com
}

of benzene as a carcinogen, the American Conference of Governmental Industrial Hygienists (ACGIH) lowered its airborne time weighted average (TWA) threshold limit value (TLV) to $0.5 \mathrm{ppm}$ in 1990 (ACGIH, 2001), and the Ministry of Employment and Labor in Korea also reduced the exposure criterion from $1 \mathrm{ppm}$ to $0.5 \mathrm{ppm}$ in 2016 (MOEL, 2016).

Even after the acknowledgement of its hazard, benzene is still included in petroleum-derived products (PDPs) not because it is used for a specific purpose but it persists as an impurity (Kopstein, 2006). It is not only technically challenging to eliminate benzene remaining as an impurity but is also expensive to improve the impurity removal efficiency. As such, benzene is not fully eliminated but still continues to be included in petrochemical products used for industrial purposes. Therefore, it is warranted that the Material Safety Data Sheet (MSDS) of petrochemical products must provide clear information on inclusion of benzene in such products. Under the current Occupational Safety and Health Act in Korea (OSHAct), a presence of a carcinogen should be specified in the MSDS when it represents $0.1 \%$ or higher in the mixture (MOEL, 2013). However, it has been argued that in practice, unlike regulations, benzene is often not included in MSDSs if the 
content is less than $0.1 \%$, resulting in potential exposures of workers handling petrochemical products without recognizing the presence of benzene (Kopstein, 2006).

Among 34 cases of hematopoietic diseases from 1992 to 2000 claimed in Korea, 8 cases were accepted as those related to benzene exposure and included degreasing (2 cases), painting ( 2 cases), and gluing ( 2 cases). A case of a worker with CLL who used $100 \%$ benzene as degreasing solvent at a telecommunication company was upheld by the court (Kang et al., 2005). In 2012, the Occupational Safety \& Health Research Institute (OSHRI) of Korea Occupational Safety and Health Agency (KOSHA) reported ALL in solvent-handling workers in the tire manufacturing business, ALL in thinner-handling workers in truck manufacturing, AML in gasoline-handling workers in vehicle manufacturing, and myelodysplastic syndrome in workers using printed circuit board pre-treatment and plating chemicals in the printing industry, and benzene, which may have been included at a trace amount, was suspected as the occupational cause of leukemia (OSHRI, 2012). Nevertheless, currently there are not many investigations on the benzene content in domestically available petrochemical products and also assessments of potential exposures to workers handling petrochemicals. The benzene data in the PDPs reported in the published literature written in English language were reviewed by Williams et al. (2008). However, the amount of benzene in the PDPs actually used in Korea has not been reported.

Against this background, the objectives of this article are (a) to review how many benzene-containing PDPs have been used in Korea; (b) to estimate inhalable benzene exposure level of workers handling benzene-containing PDPs based on the benzene exposure data reported in literatures, and (c) to demonstrate that the highly refined reagents can still contain benzene over $0.1 \%$ by weight even when the MSDS does not list benzene as an ingredient.

\section{METHODS}

\section{Literature Search and Data Analysis}

All available data on benzene-containing products existing in Korea until 2012 were collected from prior studies, reports, and epidemiological surveys using the Research Information Sharing Service (RISS: http://www.riss.kr) operated by the Korea Education \& Research Information Service (KERIS). For benzene-related literatures, search terms of "benzene," "benzene containing," "benzene including," "benzene containing substance," "benzene organic solvent," "benzene printing," "benzene paint," "benzene gasoline" and "benzene thinner" were used singly or in combination in the RISS. Additional epidemiological survey reports conducted between 1997 and 2012 by the OSHRI under the OSHAct were selected as they provided the benzene content. All data were organized by setting the content as $0.1 \%$ for data reported as " $>0.1 \%$."

A total of 128 published literatures were collected, of which 8 (Ro, 1975; Lee et al., 1990; Shin, 1995; Paik et al., 1998; Song et al., 2000; Roh et al., 2001; Lee et al., 2003; Kim et al., 2006) were used as they provided benzene content information. In addition, we selected data from 43 cases reporting benzene content out of 114 unpublished epidemiological survey reports (OSHRI, 2013) conducted between 1997 and 2012 by the OSHRI under the OSHAct. Finally, a total of 112 data sets with 131 bulk samples for benzene content information were analyzed by product types. The benzene data contained in the PDPs are summarized in terms of the sample analysis year, PDPs used industry, PDPs type, analysis method and content calculation method (weight ratio, volume ratio, etc.). If there is no information on the sample analysis year, it is replaced with the publication year.

We used the arithmetic mean (AM) as a representative value for analysis of measurements, as the best summary measure of exposure for epidemiologic studies of chronic disease (Seixas et al., 1998). If only the number of measurements and either the geometric mean (GM) and geometric standard deviation (GSD) were provided, a lognormal distribution was assumed and Eq. (1) was used to provide an estimate of AM (Aitchison and Brown, 1963).

$\mathrm{AM}=\mathrm{GM} \times \exp \left[1 / 2 \times(\ln (\mathrm{GSD}))^{2}\right]$

For the benzene content presented with a minimummaximum range, the AM was calculated with Eq. (2) by assuming a lognormal distribution according to the following method: First, the midpoint of the log transformed minimum and maximum values provided an estimate of the mean of the log-transformed levels $\left(\widehat{\mu_{L}}\right)$; second, the difference between log-transformed minimum and maximum were divided by four as an estimate of the standard deviation of the log-transformed levels $\left(\widehat{\sigma_{L}}\right)$; and finally, AM was calculated using the following formula:

$\mathrm{AM}=\exp \left[\widehat{\mu_{L}}+1 / 2 \times{\widehat{\sigma_{L}}}^{2}\right]$

When analyzing data collected based on different numbers $(\mathrm{N})$ of observations, it is appropriate to weight each average by a weight that is proportional to the inverse of the variance of the mean (Park et al., 2009). Because we did not have variance estimates, weighted arithmetic means (WAMs) were calculated with Eq. (3).

$\mathrm{WAM}=\left(\mathrm{N}_{1} \times \mathrm{AM}_{1}+\mathrm{N}_{2} \times \mathrm{AM}_{2}+\ldots+\mathrm{N}_{\mathrm{n}} \times \mathrm{AM}_{\mathrm{n}}\right) / \mathrm{N}_{\mathrm{t}}$

\section{Bulk Analysis of Benzene Content in Reagents with High Purity}

On the basis of literature review (Fedoruk et al., 2003; Kopstein, 2006; Williams et al., 2008), reagents that are likely to contain benzene were chosen, such as $n$-hexane, $n$-heptane, cyclohexane, ethylbenzene, toluene, trichloroethylene and xylene. There are two reasons for selecting reagents to confirm the benzene content in PDPs: First, as reagents have higher purity than industrial-grade products, if benzene is detected in reagents, it can be argued based on this conservative approach that industrialgrade products would have a higher content, and second, as this study is targeting products containing trace amounts of benzene, reagents were chosen as their higher purity 
would provide a lower benzene content than in industrialgrade items.

To investigate the difference according to manufacturing year, products with the earliest to the latest manufacturing dates were collected among reagents that are commercially available in Korea. The difference according to country of origin and manufacturer was also examined. Finally, a total of 32 reagents manufactured from 2004 to 2013 were collected. MSDSs and labeling information of reagents were also collected to compare the results of analysis. If an MSDS has not been provided along with a reagent, it was obtained by inquiring to the manufacturer or supplier.

For the bulk sample analysis, $1-\mu \mathrm{L}$ aliquots of the samples were directly injected into gas chromatograph (GC) equipped with a mass spectrometer (TurboMass Gold, PerkinElmer, Norwalk, CT, USA) for analysis of the benzene content (weight) in reagents (weight). The temperature of the GC capillary column $(60 \mathrm{~m} \times 0.25 \mathrm{~mm} \times 1.0 \mu \mathrm{m}$; VB-1, Valco Instruments Co. Inc.) was kept at $40^{\circ} \mathrm{C}$ for $5 \mathrm{~min}$, and then ramped to $250^{\circ} \mathrm{C}$ at a rate of $4^{\circ} \mathrm{C} \min ^{-1}, 5^{\circ} \mathrm{C} \mathrm{min}{ }^{-1}$, and $20^{\circ} \mathrm{C} \mathrm{m^{-1 }}$ with a final hold of $1 \mathrm{~min}$. The temperatures of the injection port and detector were maintained at $200^{\circ} \mathrm{C}$ and $250^{\circ} \mathrm{C}$, respectively. The flow rate of the carrier gas helium (purity of $99.999 \%$ ) was $1.5 \mathrm{~mL} \mathrm{~min}^{-1}$. Mass range was scanned from 35 to 350 atomic mass unit through selected ion recording mode. The limit of detection (LoD) for benzene (HPLC grade $\geq 99.9 \%$, Sigma-Aldrich) was $0.005 \mathrm{mg} \mathrm{L}^{-1}$.

\section{RESULTS}

\section{Content of Benzene in PDPs Used from 1975 to 2012 in Korea}

From literature review, a total of 112 data sets with benzene content were found and detailed information was listed in Appendix A. The distribution of the benzene content in each product between 1974 and 2012 was summarized in Table 1.

In terms of number of bulk samples, thinner accounted for the largest proportion of retrieved data $(n=51)$, followed by coating materials $(n=23)$, gasoline $(n=15)$, solvent $(n$ $=12)$, diluent $(n=8)$ and adhesive $(n=4)$. Although the number of samples was small, information on the benzene content in cleaning products, hardener, ink, printing agent, raw material, accelerant, anti-rusting oil, ethyl benzene, fuel, toluene and waste was also collected.

In terms of the maximum benzene content in each product, the highest level was reported for thinner, up to $56.7 \%$ (v/v). Thinner also showed the widest content distribution, ranging between $0.00018 \%$ and $56.7 \%$. Of products used prior to 1980 , only thinner was reported that the WAM benzene content was $12.6 \%$ and among products used from 1981 to 1999 and after 2000, all but diluent had a mean over $0.1 \%$.

In PDPs used after 2000, both the minimum and maximum benzene content exceeded the MSDS carcinogenicity listing criterion of $0.1 \%$ for adhesive (minimum: $0.13 \%$, maximum: $5.7 \%)$, cleaning products $(0.17 \%, 1.5 \%)$, raw material $(1.1 \%, 10 \%)$ and solvent $(0.5 \%, 8.96 \%)$.

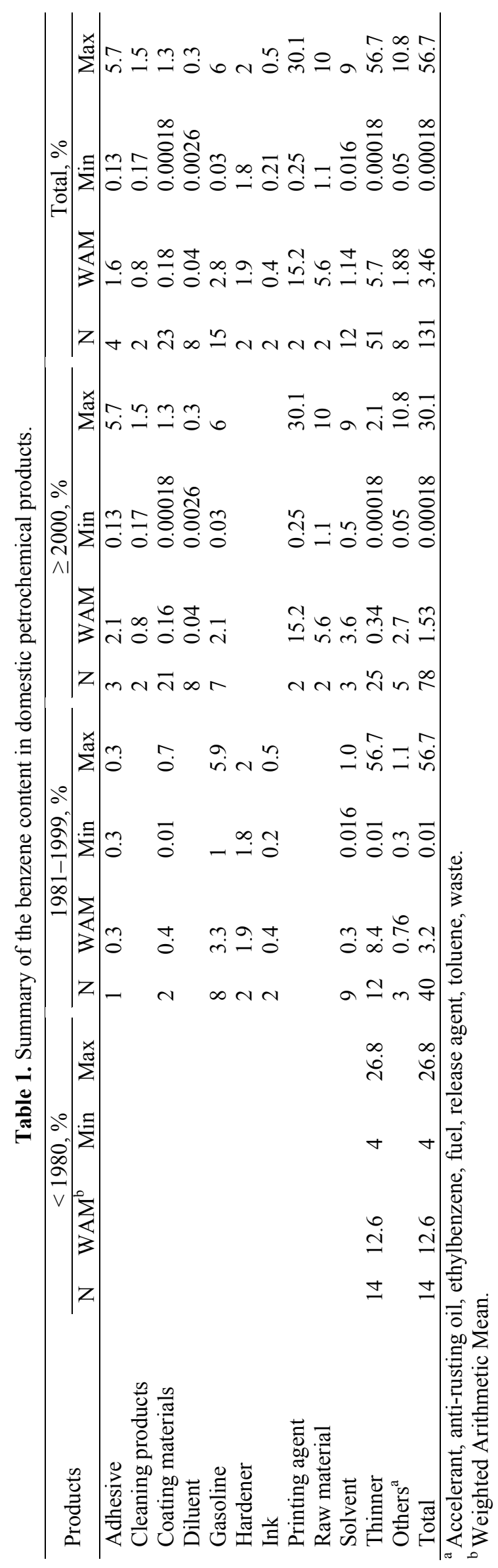


Comparison between Bulk Content and Airborne Concentration of Benzene

We compared the data which have both information of the bulk content and exposure level of benzene to workers handling those products (Table 2).

Ro (1975) reported that 14 thinner products used for dilution or washing contained benzene at $12.6 \%$ on average and measured airborne concentrations in 2 painting workplaces using these products. Workplace A had a local exhaustive ventilation (LEV) system with 2 horse power (HP) in $85 \mathrm{~m}^{2}$ and Workplace B had one LEV with three HP and three LEVs with $2 \mathrm{HP}$ in $92 \mathrm{~m}^{2}$. Airborne samples were analyzed with ultraviolet spectroscopy and reported as mean 30 ppm in Workplace A and 10 ppm in Workplace B.

Song et al. (2000) measured the benzene content in gasoline and airborne exposure concentrations for fuelfilling workers in 7 gas stations in downtown areas and highway rest stops. Airborne concentrations were measured with low-flow pumps and charcoal tubes and analyzed with the gas chromatograph-flame ionization detector (GC-FID). Samples were collected for each of 2 work shifts (07:00 15:00, 15:00-22:00). Area samplers were placed on top of oil supply machines. Personal sampling results ranged between $0.003 \mathrm{ppm}$ and $0.2 \mathrm{ppm}$, and area sampling measurements ranged between $0.004 \mathrm{ppm}$ and $0.31 \mathrm{ppm}$. Volatile ingredients including benzene of gasoline bulk samples used in gas stations were also analyzed with GCFID and found to contain benzene between 2.1\% and 5.9\%.

According to a study by Roh et al. (2001), benzene was detected at $1.28 \%$ in 1 organic solvent used for dry cleaning and partial stain removal in 20 laundries. Airborne concentrations were measured with low-flow pumps and charcoal tubes, and sampling was conducted for 6 or more hours on days when dry cleaning took place. Samples were collected around workers' breathing zone, workstations and washing machines, and analyzed with GC-FID. From personal sampling, the arithmetic mean concentration was $1.43 \mathrm{ppm}$ and from area sampling, the arithmetic mean airborne concentration was $1.19 \mathrm{ppm}$ around workstations and $1.48 \mathrm{ppm}$ around dry cleaning machines.

From an epidemiological survey in a tire manufacturing factory (OSHRI, 2013), a solvent spray solution used in an extrusion division was analyzed with GC-MS and the benzene content in evaporated ingredients ranged between $0.32 \%$ and $0.40 \%$. Work environment was monitored for the entire 3-shift workers and samples were collected using low-flow pumps and charcoal tubes. Short-term benzene exposure concentration during a mixing operation was $2.16 \mathrm{ppm}$ and personal sampling results from 14 workers ranged between $0.31 \mathrm{ppm}$ and $0.84 \mathrm{ppm}$.

In a synthetic leather manufacturing factory, coating materials, solvent, catalyst and hardener were analyzed with GC-MS, and found to contain benzene between $0.7 \%$ and $2.0 \%$ (OSHRI, 2013). Airborne concentrations were measured in July with a relatively high evaporation rate of benzene, and at the time of monitoring, only an afternoon shift was taking place due to a reduced workload compared to usual days. Airborne exposure concentrations ranged between $0.02 \mathrm{ppm}$ and $0.05 \mathrm{ppm}$.
In an epidemiological survey in a vehicle manufacturing factory (OSHRI, 2013), the benzene content in gasoline used in vehicle instrument cluster development testing was $4 \%$ according to the product specification. Vehicle instrument cluster refer to the instrument cluster which collects various information about the car such as speed, rotation per minute (RPM), fuel quantity, coolant temperature gauge, etc. at a glance. During development testing of vehicle instrument cluster, personal sampling results in 2 workers ranged between $3.5 \mathrm{ppm}$ and $6.68 \mathrm{ppm}$. Area sampling measurements ranged between $2.67 \mathrm{ppm}$ and $4.0 \mathrm{ppm}$.

In an epidemiological survey in a speaker cone paper manufacturing factory (OSHRI, 2013), benzene content in adhesive bond and airborne benzene exposure concentrations during working hours were measured. Bond ingredients were analyzed with GC-MS, and detected benzene in the bond used for kit bonding and lacquer bonding was at $0.13 \%$ and $5.66 \%$, respectively. Airborne concentrations were measured with charcoal tubes near a worker's breathing zone and on workstations close to the worker's respiratory system. 8-h weighted mean airborne concentration was $0.05 \mathrm{ppm}$ for kit bonding and lead wire insertion, and the area sampling result at the kit bonding place and the area between lacquer spraying and kit bonding was $0.05 \mathrm{ppm}$ and $0.06 \mathrm{ppm}$, respectively. There was no ventilation system in the workplace.

In epidemiological survey conducted by KOSHA (OSHRI, 2013) at a painting factory, benzene was detected at $0.01 \%$ and $0.05 \%$ in 2 samples of used paints, and airborne concentrations ranged between $0.01 \mathrm{ppm}$ and $6.55 \mathrm{ppm}$ for block painting at a dock and operations inside a ship and in a painting shop.

KOSHA (OSHRI, 2013) monitored a raw material filling operation in a lubricating oil production factory and reported that the airborne exposure concentrations of the main worker who personally observed the filling and a supportive worker were $0.43 \mathrm{ppm}$ and $0.31 \mathrm{ppm}$, respectively. Sampling was conducted for a 2-h work shift as the filling operation takes about 2 hours and occurs approximately once every 2 months. The lubricating oil was analyzed and found to contain benzene at $1.1 \%$.

\section{Confirmation of Benzene Content in Reagents}

A total of 32 products of 7 reagents, including cyclohexane, ethylbenzene, $n$-heptane, $n$-hexane, toluene, trichloroethylene and xylene were analyzed to confirm the trace level of benzene.

Table 3 shows the summary of the results of benzene analyses in 32 bulk samples. Benzene was detected in 13 products of 6 reagent chemicals ( $n$-heptane products being the exception). The maximum benzene content was $0.166 \%$ in trichloroethylene, followed by $0.146 \%$ in ethylbenzene, $0.064 \%$ in toluene, $0.009 \%$ in xylene and $0.004 \%$ in $n$-hexane. In some of ethylbenzene (R-8, R-9) and trichloroethylene (R-28) reagents with detected benzene, the level exceeded the MSDS carcinogenicity listing criterion of $0.1 \%$. However, no reagents had benzene information listed in MSDS or labeling as an ingredient. 


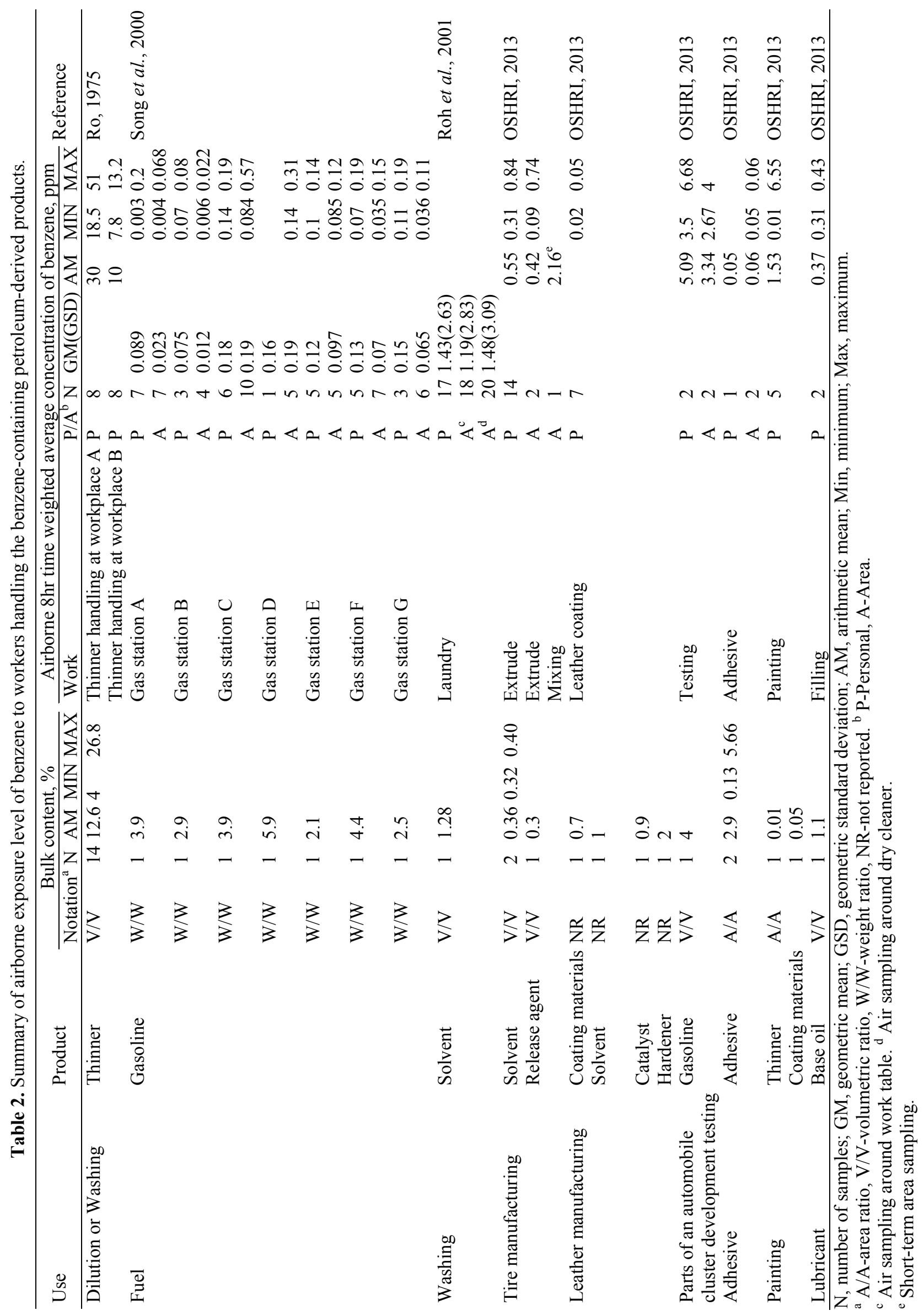


Table 3. Experimental evidences on the evaluation of the benzene content in reagent chemicals.

\begin{tabular}{|c|c|c|c|c|c|c|c|c|c|}
\hline \multirow{2}{*}{ ID } & \multirow{2}{*}{ Reagent } & \multicolumn{3}{|c|}{ Manufacturing } & \multicolumn{2}{|c|}{ Purity, \% } & \multicolumn{3}{|c|}{ Benzene content, $\%$} \\
\hline & & Nation & Company & Year & Labeling & MSDS & Labeling & MSDS & Bulk analysis \\
\hline $\mathrm{R}-1$ & Cyclohexane & Korea & $\mathrm{A}$ & 2013 & 99.5 & 100 & $\mathrm{NI}^{\mathrm{a}}$ & NI & $\mathrm{ND}^{\mathrm{b}}$ \\
\hline $\mathrm{R}-2$ & Cyclohexane & Korea & $\mathrm{A}$ & 2013 & 99.8 & 100 & NI & NI & ND \\
\hline $\mathrm{R}-3$ & Cyclohexane & Japan & $\mathrm{B}$ & 2004 & 98 & $\mathrm{NI}^{\mathrm{b}}$ & NI & NI & ND \\
\hline $\mathrm{R}-4$ & Cyclohexane & Japan & $\mathrm{B}$ & 2013 & 99.5 & NI & NI & NI & 0.003 \\
\hline R-5 & Cyclohexane & Japan & $\mathrm{C}$ & 2013 & $>99.5$ & $>99.5$ & NI & NI & ND \\
\hline $\mathrm{R}-6$ & Cyclohexane & U.S.A. & $\mathrm{D}$ & 2013 & 99.5 & NI & NI & NI & ND \\
\hline $\mathrm{R}-7$ & Ethylbenzene & Japan & $\mathrm{E}$ & 2012 & Minimum 98.0 & Minimum 98.0 & NI & NI & ND \\
\hline $\mathrm{R}-8$ & Ethylbenzene & Japan & $\mathrm{C}$ & 2013 & $>99.0$ & $>99.0$ & NI & NI & 0.142 \\
\hline R-9 & Ethylbenzene & U.S.A. & $\mathrm{D}$ & 2010 & 99.8 & $\leq 100$ & NI & NI & 0.146 \\
\hline $\mathrm{R}-10$ & n-Heptane & Korea & A & 2013 & $>98$ & 100 & NI & NI & ND \\
\hline $\mathrm{R}-11$ & n-Heptane & Korea & A & 2013 & $>99$ & 100 & NI & NI & ND \\
\hline $\mathrm{R}-12$ & n-Heptane & Japan & B & 2004 & 98 & NI & NI & NI & ND \\
\hline $\mathrm{R}-13$ & n-Heptane & Japan & $\mathrm{B}$ & 2013 & $>99.0$ & $\mathrm{NM}^{\mathrm{c}}$ & NI & NM & ND \\
\hline $\mathrm{R}-14$ & n-Heptane & Japan & $\mathrm{C}$ & 2013 & $>99.0$ & $>99.0$ & NI & NI & ND \\
\hline $\mathrm{R}-15$ & n-Hexane & Korea & A & 2013 & $>95.0$ & 100 & NI & NI & 0.004 \\
\hline $\mathrm{R}-16$ & n-Hexane & Korea & A & 2013 & $>96.0$ & 100 & NI & NI & ND \\
\hline $\mathrm{R}-17$ & n-Hexane & Japan & $\mathrm{B}$ & 2007 & $>96.0$ & NI & NI & NI & ND \\
\hline $\mathrm{R}-18$ & n-Hexane & Japan & $\mathrm{B}$ & 2013 & $>96.0$ & NM & NI & NM & ND \\
\hline $\mathrm{R}-19$ & n-Hexane & U.S.A. & $\mathrm{D}$ & 2013 & 95 & $\mathrm{NI}$ & NI & NI & ND \\
\hline $\mathrm{R}-20$ & Toluene & Korea & A & 2012 & $>99.5$ & 100 & NI & NI & 0.064 \\
\hline $\mathrm{R}-21$ & Toluene & Korea & A & 2013 & $>99.7$ & 100 & NI & NI & 0.063 \\
\hline $\mathrm{R}-22$ & Toluene & Japan & $\mathrm{B}$ & 2004 & $>99.0$ & $\mathrm{NI}$ & NI & NI & 0.014 \\
\hline $\mathrm{R}-23$ & Toluene & Japan & $\mathrm{B}$ & 2004 & $>99.5$ & $\mathrm{NI}$ & NI & NI & ND \\
\hline $\mathrm{R}-24$ & Toluene & Japan & $\mathrm{B}$ & 2012 & $>99.7$ & $\mathrm{NI}$ & NI & NI & ND \\
\hline $\mathrm{R}-25$ & Toluene & Japan & $\mathrm{G}$ & 2004 & 99.7 & NM & NI & NM & 0.004 \\
\hline $\mathrm{R}-26$ & Toluene & Japan & $\mathrm{C}$ & 2013 & $>99.5$ & $>99.5$ & NI & NI & 0.006 \\
\hline $\mathrm{R}-27$ & Trichloroethylene & Korea & $\mathrm{A}$ & 2010 & $>98.5$ & $98.5-100$ & NI & NI & ND \\
\hline $\mathrm{R}-28$ & Trichloroethylene & Japan & B & 2004 & 98 & NM & NI & NM & 0.166 \\
\hline $\mathrm{R}-29$ & Trichloroethylene & Japan & $\mathrm{E}$ & 2013 & $>99.5$ & NM & NI & NM & ND \\
\hline $\mathrm{R}-30$ & Xylene & Korea & A & 2011 & $>80$ & 100 & NI & NI & 0.009 \\
\hline $\mathrm{R}-31$ & Xylene & Japan & B & 2004 & $>80$ & $\mathrm{NI}$ & NI & NI & 0.006 \\
\hline $\mathrm{R}-32$ & Xylene & Japan & $\mathrm{F}$ & 2004 & $>85$ & $\mathrm{NM}$ & $\mathrm{NI}$ & NM & 0.006 \\
\hline
\end{tabular}

MSDS, material safety data sheet.

${ }^{\mathrm{a}}$ No information, ${ }^{\mathrm{b}}$ Not detected, ${ }^{\mathrm{c}}$ No MSDS.

\section{DISCUSSION}

In Korea, domestic benzene production has steadily increased from 1.28 million tonnes in 1995 to 3.23 million tonnes in 2012. Benzene is mainly used as raw materials for styrene monomer, phenol, cyclohexane, aniline, maleic anhydride, and alkylbenzene (KPIA, 2012). Benzene could be also contained as impurities in PDPs such as cleaning agents, adhesives and thinners, which are mainly used in the workplace. However, these products often do not provide benzene information in the MSDS. Therefore, this study attempts to collect as much reported data as possible on the benzene content in PDPs used in Korea.

Based on the Korean domestic data collection, thinner had the highest benzene content of $56.7 \%$ in 1997 , followed by $30.1 \%$ for printing agent in $2005,8.96 \%$ for solvents used at maintenance and repair services of motor vehicles in 2005, and $6.0 \%$ for gasoline in 2002 (Table 1). The results of this study showed that Korean PDPs contain more benzene content than the data reported by Williams et al.
(2008), who reviewed the benzene content data of PDPs reported in the literature from 1956 to 2003. According to their report, the benzene content of petroleum naphthas and other solvents sometimes used in the rubber coating industry was found to equal or exceed $1 \%$ in the mid-1950s and early 1960s, with benzene concentrations as high as $9 \%$ measured for some naphtha solvents. Hexane, heptane, rubber solvents, lacquer diluents, and toluene also typically contained benzene concentrations at or above $0.1 \%(\mathrm{v} / \mathrm{v})$ prior to 1978. However, the benzene content of PDPs declined significantly after the late 1970s and early 1980s and is currently $<0.1 \%(\mathrm{v} / \mathrm{v})$ for most commercial products.

Among the 112 data points, the data on thinner products composed the largest share (51 points), and the content of benzene showed a wide range from $0.00018 \%$ to $56.7 \%$. The level of benzene content in the thinner product showed different characteristics depending on the type of thinner. Table 4 compares the results of four studies that report the amount of benzene contained in the thinner according to the type of thinner. Ro (1975) analyzed the benzene content 
Table 4. Comparison of the benzene content in thinners by the type of thinner.

\begin{tabular}{|c|c|c|c|c|}
\hline \multirow{2}{*}{ Type of thinner } & \multicolumn{4}{|c|}{ Benzene content, $\%$} \\
\hline & Ro (1975) & Paik et al. (1998) & Lee et al. (2003) & Kim et al. (2006) \\
\hline Automobile painting thinner & & $\mathrm{ND}^{\mathrm{b}}$ & $0.00018-0.00747$ & \\
\hline Coating thinner & & 56.7 & & ND \\
\hline Degreasing thinner & & 23.3 & & \\
\hline Electronic thinner & & 0.1 & & \\
\hline Enamel thinner & & 0.3 & & $0.3-1.2$ \\
\hline Epoxy thinner & & 1.3 & & $0.3-0.5$ \\
\hline Lacquer thinner & & $0.6-2.8$ & & \\
\hline $\mathrm{NC}^{\mathrm{a}}$ & $4.0-26.8$ & & & \\
\hline
\end{tabular}

${ }^{\mathrm{a}}$ Not classified but toluene-based.

${ }^{\mathrm{b}}$ Not detected.

among the 14 thinner products sold in 1974, but no information on thinner types was reported. It is reported that the cause of benzene in thinner is the impurity of industrial toluene, which is the main ingredient in thinner. The benzene and toluene concentrations in each thinner reported in Ro's study are positively correlated $(\mathrm{R}=0.68)$ as shown in Fig. 1, and benzene can be estimated to be about $28 \%$ of the toluene content. Paik et al. (1998) reported that toluene is the most commonly detected substance in thinners and benzene is not detected in automotive paint thinners. Instead of benzene, xylene, toluene, cellosolve acetate, butyl cellosolve and butyl acetate were frequently detected in automotive paint thinners in Paik's study. In fact, Lee et al. (2003) visited 7 automobile manufacturers and collected 70 paint thinners used in painting process and analyzed their benzene content. As a result, it was reported that trace amounts of $0.00018-0.00747 \%$ were detected in 7 thinners only. In addition, xylene was detected most frequently, and toluene and cellosolve materials were identified, similar to Paik's reports.

The content of benzene in all PDPs and thinner products showed a tendency to decrease with the year as shown in Fig. 2. However, until 2010, the maximum benzene content in all PDPs and thinner products exceeded $1 \%$ and $0.1 \%$ respectively. In terms of gasoline, benzene has been used to improve the octane value. However, with awareness of risks of benzene, the Korean criterion of benzene content in gasoline was gradually lowered from $6.0 \%$ in 1992 to $5 \%$ in $1996,4 \%$ in $1998,2 \%$ in $2000,1.5 \%$ in 2002 and $0.7 \%$ in 2009 (Sheen, 2001; ME, 2012). Despite such regulation, analysis results showed that the benzene content in gasoline still exceeds the 2002 criterion of $1.5 \%$, with some data reporting the benzene content as $6.0 \%$ in 2002 and $4.0 \%$ in 2007; and although the criterion for benzene in gasoline was reduced to $0.7 \%$ in $2009,0.86 \%$ was reported in 2012. Tsai et al. (2017) reported that the benzene content of commercial unleaded gasoline made in Taiwan, United States and Europe is $0.52 \%(\mathrm{v} / \mathrm{v}), 0.50-0.54 \%(\mathrm{v} / \mathrm{v})$ and not available, respectively. Reducing the benzene content in gasoline is crucial for reduction of the benzene emissions during the combustion of automotive vehicles. Yao et al. (2017) investigated organic air pollutant emissions from motorcycles by using various ethanol-gasoline blends. They reported that the content of benzene in commercial unleaded gasoline is $0.6 \%$, and that as the mixing ratio of ethanol increases, the content of benzene decreases to $0.1 \%$. When the mixing ratio of ethanol increases, the benzene emissions $\left(\mathrm{mg} \mathrm{km}^{-1}\right)$ decreased from $8.9 \mathrm{mg} \mathrm{km}^{-1}$ with commercial gasoline to $4.2 \mathrm{mg} \mathrm{km}^{-1}$ with $30 \%(\mathrm{v} / \mathrm{v})$ ethanol in gasoline.

Roh et al. (2000) reported that dry cleaning solvents used in Korean laundries were petroleum-based and contained more than $1 \%$ benzene. In 1990 , about $53 \%$ of world demand for tetrachloroethylene was for dry cleaning used in USA, western Europe and Japan, and it was the cleaning fluid used by about $75 \%$ of all dry cleaners (Linak et al., 1992). However, more than $90 \%$ of the laundry solvents used in Korea until 2000 were petroleum-based solvents. Jeong et al. (2005) also investigated aromatic hydrocarbons contained in petroleum-based solvents used at 13 laundries in 2002, but only xylene was detected. Jeong et al. (2005) explained that domestic refiners are converting aromatics into naphthene compounds by adding a hydrogenation process to eliminate aromatic odors as much as possible.

Few studies have examined the benzene content in PDPs and personal exposure concentrations of handling workers. Only 3 of the 8 articles investigating benzene content in PDPs reported airborne benzene exposure (Table 2). The benzene content in a product is one of the key factors that determine the benzene exposure level. However, exposure concentrations in air are affected by the conditions under which benzene containing products are handled, such as ventilation conditions, workplace temperatures, and length of time to handle the benzene-containing products (Kopstein, 2006). In a study by Song et al. (2000), gas station operators who handled gasoline with a benzene content of 2.1-5.9\% were exposed to benzene in air at a concentration of $0.003-$ $0.2 \mathrm{ppm}$. On the other hand, Roh et al. (2001) reported that the geometric mean benzene exposure level of workers handling dry cleaning solvent containing $1.28 \%$ of benzene was 1.43 ppm. Laundry workers work indoors, but because the gas station workers work outdoors, there is a high probability that the benzene concentration in the air will be diluted.

To estimate benzene exposures of workers handling products containing trace amounts of benzene, a Similar Exposure Group (SEG) method can be used. Exposure estimation using the SEG has been verified in a simulation 


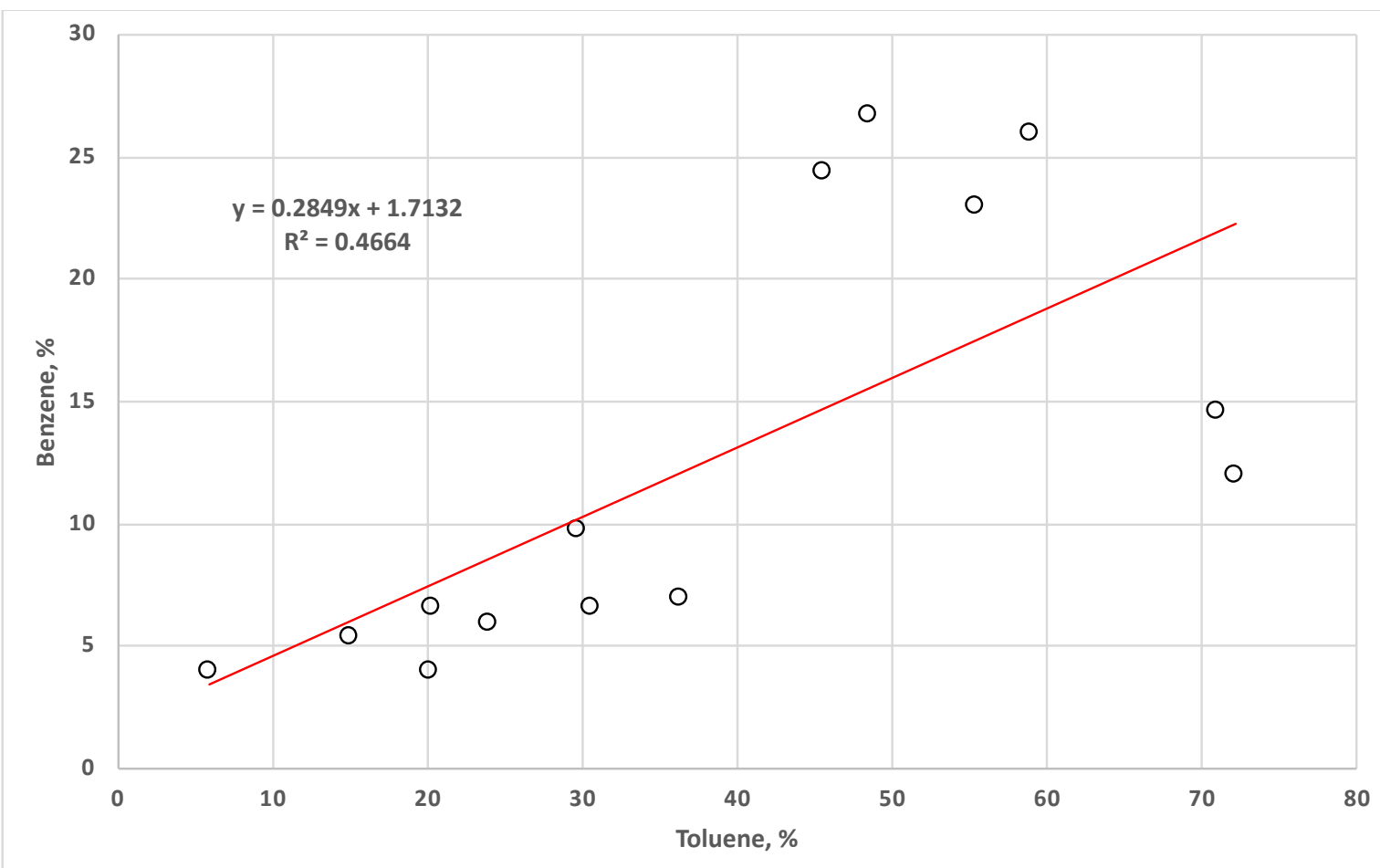

Fig. 1. Correlation between benzene and toluene content in 14 thinner products used in 1974 (Ro, 1975).

by Fedoruk et al. (2003). Workers who handle products with known benzene content and airborne exposure concentrations are used as a "reference SEG." Those who handle benzenecontaining similar products under comparable working conditions are classified as a "compared SEG." The exposure level of the "compared SEG" is estimated using a linear function in which the airborne exposure level increases in proportion to the benzene mole fraction according to Raoult's law. In other words, as presented in Eq. (4), the airborne benzene exposure concentration $\left(\mathrm{C}_{\mathrm{ppm}}\right.$, SEG-C $)$ of the "compared SEG" is estimated by calculating the ratio of the benzene content $\left(\mathrm{R}_{\mathrm{Bz}}\right)$ in the product used by the "compared SEG" to that of the "reference SEG" multiplied with the airborne exposure level $\left(\mathrm{C}_{\mathrm{ppm}}\right.$, SEG-R $)$ of the "reference SEG."

$\mathrm{C}_{\mathrm{ppm}, \text { SEG-C }}=\mathrm{R}_{\mathrm{Bz}} \times \mathrm{C}_{\mathrm{ppm}, \mathrm{SEG}-\mathrm{R}}$

In order to predict the benzene exposure well, there should be sufficient information on the operating conditions and work environment for the "reference SEG." Therefore, among the data on the benzene content in PDPs used in Korea and airborne exposure concentrations for handling workers, data that provide relatively enough information on work circumstances were used for SEG-based benzene exposure estimation, and the results are presented in Table 5.

Ro (1975) reported that the mean benzene content was $12.6 \%$ for 14 thinner products that were available at the time of the study and the airborne exposure concentration was $30 \mathrm{ppm}$ for thinner-handling painting workers in a workplace with one LEV. Assuming the benzene content in thinner as $0.21 \%$, workers' airborne exposure level under similar work conditions can reach $0.5 \mathrm{ppm}$, the current exposure criterion in Korea. Even at $0.1 \%$ of benzene in thinner, the exposure level can reach around half the level of the exposure criterion of $0.5 \mathrm{ppm}$.

According to the epidemiological survey for a shipbuilding industry performed in 2002 by the KOSHA (OSHRI, 2013), the mean airborne exposure level of benzene was $0.92 \mathrm{ppm}$ for spray painting workers, 0.06 ppm for brush painting workers and up to $6.5 \mathrm{ppm}$ for painting workers in a confined block. Under similar work conditions, use of thinner with a benzene content of $0.1 \%$ and paint with a benzene content of $0.5 \%$ in a confined place may lead to a high-level exposure up to $65 \mathrm{ppm}$.

In an epidemiological survey of a lubricating oil production factory conducted in 2006 (OSHRI, 2013), the exposure level of workers engaged in raw material filling containing benzene of $1.1 \%$ was 0.37 ppm. Under similar work conditions, if the benzene content is assumed as $3 \%$, the exposure level can reach double the level of domestic exposure criterion and if the benzene content is $0.3 \%$, the exposure is expected to meet the USA NIOSH recommendation exposure level of $0.1 \mathrm{ppm}$.

The MSDS is a crucial means of providing information on a chemical and serves as a basis of a comprehensive chemical management system. It is recognized as a representative tool of information communication to prevent accidents and occupational diseases and satisfy workers' right to know by disclosing hazards and risks of a chemical and enabling its safe handling. However, as shown from Table 3, content information differed between product labels and MSDSs for $11(34.4 \%)$ products and was consistent for only $5(15.6 \%)$ products. $10(31.3 \%)$ products had no 
content information in MSDSs, and MSDSs were not available for $6(18.7 \%)$ products. In case of $n$-hexane, xylene and trichloroethylene, the content on product labels and MSDSs was inconsistent in all cases. Furthermore, no product had benzene listed as an ingredient.
As indicated by this study's findings, benzene is still included in PDPs not because it is used for a specific purpose, but it remains as an impurity. Consequently, products are being distributed and used with benzene unremoved. Kopstein (2006) explained several reasons for

(a)

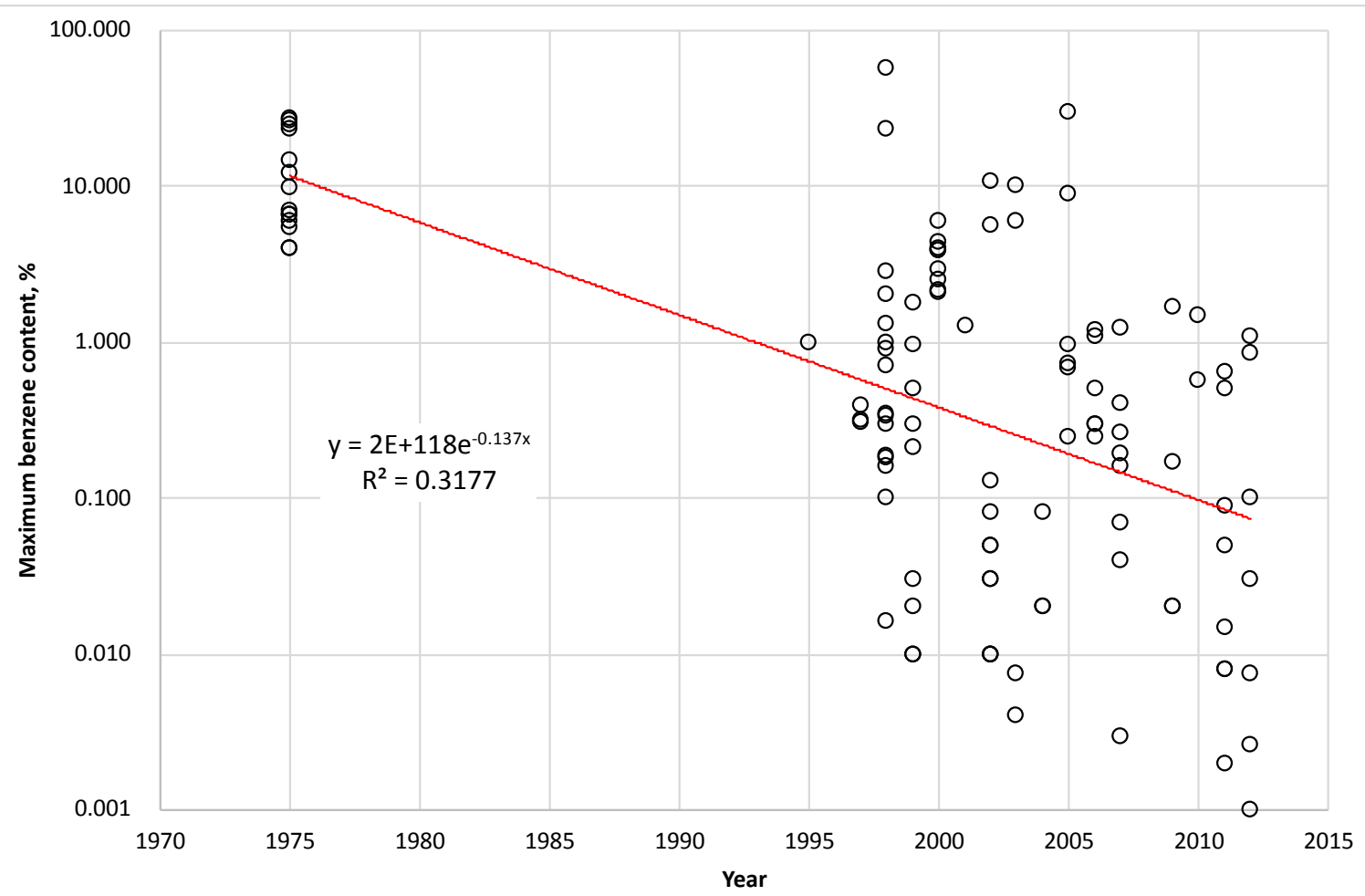

(b)

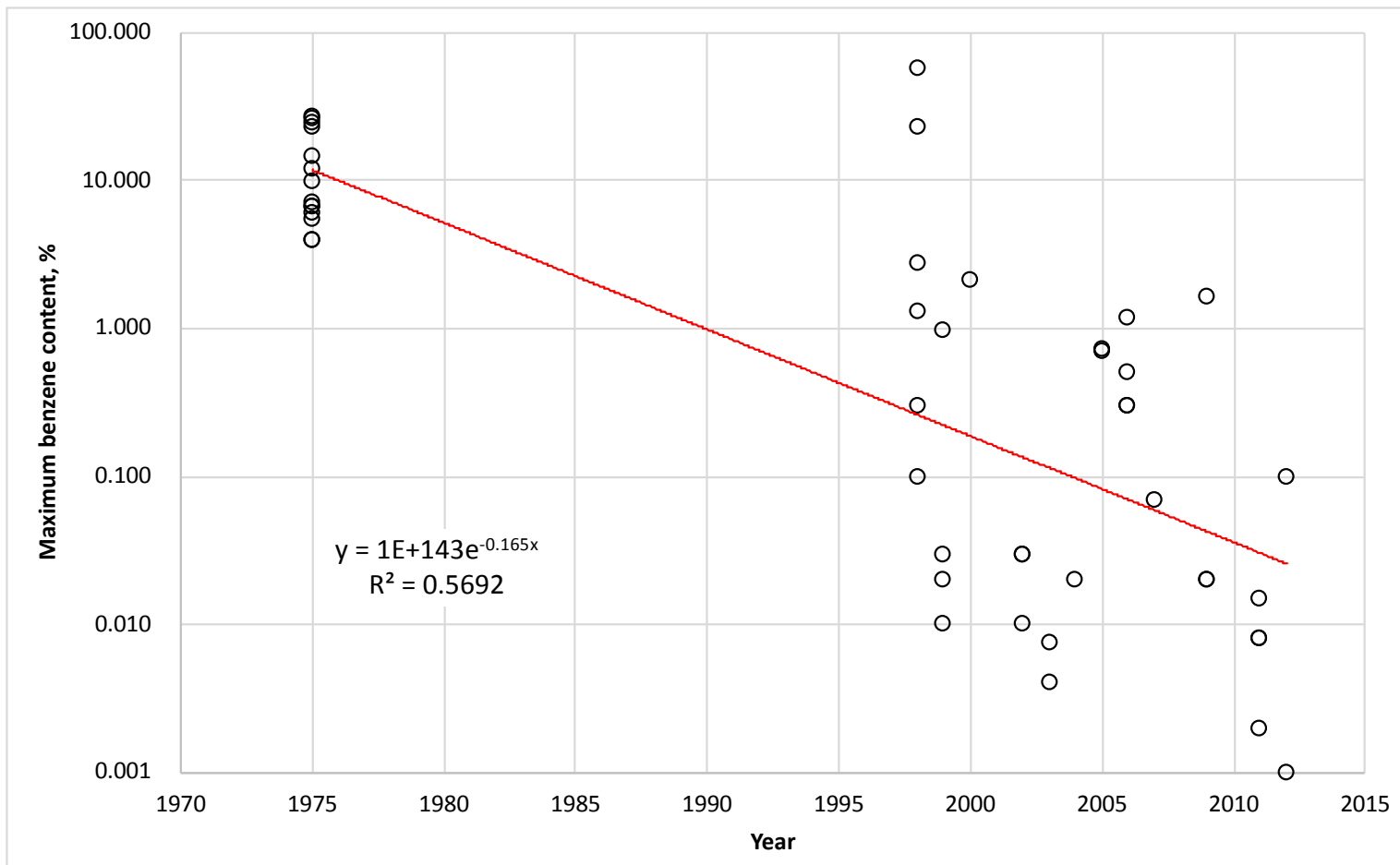

Fig. 2. Annual trends of the maximum benzene content in (a) all petroleum-derived products and (b) thinner products reported from 1975 to 2013 in Korea. 
Table 5. Estimation of the benzene concentration by using a similar exposure group.

\begin{tabular}{|c|c|c|c|c|c|c|}
\hline \multicolumn{5}{|c|}{ Reference similar exposure group } & \multicolumn{2}{|c|}{ Compared similar exposure group } \\
\hline Reference & Task & Product & $\begin{array}{l}\text { Benzene } \\
\text { content, \% } \\
\text { (1) }\end{array}$ & $\begin{array}{l}\text { Airborne benzene } \\
\text { concentration, ppm } \\
\text { (2) }\end{array}$ & $\begin{array}{l}\text { Benzene } \\
\text { content, \% } \\
(3)\end{array}$ & $\begin{array}{l}\text { Estimated airborne } \\
\text { benzene concentration, } \\
\text { ppm }(4)^{\mathrm{a}}\end{array}$ \\
\hline \multirow[t]{3}{*}{ Ro, 1975} & Painting & Thinner & 12.6 & 30 & 0.42 & 1 \\
\hline & & & & & 0.21 & 0.5 \\
\hline & & & & & 0.1 & 0.24 \\
\hline \multirow[t]{4}{*}{ OSHRI, 2013} & Painting & Thinner & 0.01 & 0.92 (spraying) & 0.1 & 9.2 \\
\hline & & Coating materials & 0.05 & & 0.5 & \\
\hline & & & & 0.06 (brushing) & & 0.6 \\
\hline & & & & 6.5 (confined space) & & 65 \\
\hline \multirow[t]{3}{*}{ OSHRI, 2013} & Filling & Base oil & 1.1 & 0.37 & 3.0 & 1 \\
\hline & & & & & 1.5 & 0.5 \\
\hline & & & & & 0.3 & 0.1 \\
\hline
\end{tabular}

$\bar{a}(4)=(2) \times(3) /(1)$.

this. First, it is technically highly challenging to eliminate benzene, and second, it incurs high expenses to improve the efficiency of benzene impurity removal so that industrialgrade petrochemical products are used without eliminating benzene. Third, in separation of a mixture, it is not technically feasible yet to separate materials with similar boiling points. Such results suggest that if the presence of benzene is not specified in the MSDS and the label of a petrochemical product, workers who handle the product will engage in operations without recognizing that the product may contain benzene.

\section{CONCLUSION}

The amount of benzene contained in petroleum-derived products is one of the key factors that determine the level of exposure. This study was conducted to assess the levels of benzene in PDPs through literature reviews reported in Korea and to estimate the inhalable benzene to which workers who handle PDPs containing trace amounts of benzene are exposed. Thinner had the highest benzene content $(56.7 \%$ in 1997$)$, followed by printing agent $(30.1 \%$ in 2005), solvent used in the maintenance and repair of motor vehicles $(8.96 \%$ in 2005$)$, and gasoline $(6.0 \%$ in 2002). The amount of benzene contained in the PDPs exhibited a declining trend over the years, but workers handling thinners containing less than $0.1 \%$ benzene were found to be exposed to concentrations above $1 \mathrm{ppm} .13$ of the 32 reagents were also confirmed to contain benzene, and the products of trichlorethylene and ethylbenzene contained more than $0.1 \%$ benzene. However, no reagents listed benzene as an ingredient or included information about it in the material safety data sheet. If there is a possibility of benzene exposure, even when the benzene content is below $0.1 \%$, specifying the presence of benzene in the MSDSs of PDPs to ensure the protection of workers is warranted. In terms of a retrospective epidemiological survey for compensation, information about benzene in PDPs is crucial evidence that demonstrates the association between illnesses in PDP-handling workers and benzene exposure. Our results provide a basis for estimating that exposure.

\section{ACKNOWLEDGMENTS}

This research was supported by Basic Science Research Program through the National Research Foundation of Korea (NRF) funded by the Ministry of Education, Science and Technology (2013-054650).

\section{SUPPLEMENTARY MATERIAL}

Supplementary data associated with this article can be found in the online version at http://www.aaqr.org.

\section{REFERENCES}

ACGIH (2001). Documentation of the threshold limit values (TLVS) and biological exposure indices (BEIS) benzene. American Conference of Governmental Industrial Hygienists, Cincinnati, $\mathrm{OH}$, USA.

Aitchison, J. and Brown, J.A.C. (1963). The lognormal distribution. Cambridge University Press, Cambridge, UK.

ATSDR (2007). Toxicological profile for benzene. U.S. Department of Health and Human Service. Agency for Toxic Substances and Disease Registry, ASTDR. Atlanta, USA, pp. 243-244.

Fedoruk, M., Bronstein, R. and Kerger, B. (2003). Benzene exposure assessment for use of a mineral spirits-based degreaser. Appl. Occup. Environ. Hyg. 18: 764-781.

IARC (2012). IARC monographs on the evaluation of carcinogenic risks to humans, chemical agents and related occupations volume $100 \mathrm{~F}$. A review of human carcinogens. International Agency for Research on Cancer, Lyon, France, pp. 257-262.

Jeong, J.Y., Yi, G.Y., Lee, N., Lee, B.K., Kim, B.Y. and Kim, K.J. (2005). An evaluation of exposure to petroleum based dry cleaning solvent used in commercial dry cleaning shops. J. Korean Soc. Occup. Environ. Hyg. 15: 19-26. 
Kang, S.K., Lee, M.Y., Kim, T.K., Lee, J.O. and Ahn, Y.S. (2005). Occupational exposure to benzene in South Korea. Chem. Biol. Interact. 153-154: 65-74.

Kim, Y.Y., Yang, S.H., Lee, J.S., Lee, H.S., Jang, K.H., Jin, K.Y., Lee, Y.I., Joo, W.H., Paik, D.H., Kang, D.O., Moon, J.Y., Cho, Y.K., Park, D.U., Yoon, C.S. and Ha, K.C. (2006). Compositions and contents of thinner and reliability of MSDS sold in Busan and Gyeongnam province. J. Korean Soc. Occup. Environ. Hyg. 16: 314 324.

Kopstein, M. (2006). Potential uses of petrochemical products can result in significant benzene exposure: MSDSs must list benzene as an ingredient. J. Occup. Environ. Hyg. 3: 1-8.

KPIA (2012). 2012 Petrochemical products handbook. Korea Petrochemical Industry Association. Seoul, Korea.

Lee, J.Y., Kim, S.J., Lee, J.T., Moon, D.H., Lee, C.U. and Pae, K.T. (1990). Determination of organic solvent mixtures in shoes manufacturing industries. Inje Med. $J$. 11: 435-445.

Lee, K.S., Kwon, H.W., Han, I.S., Yu, I.S. and Lee, Y.M. (2003). A study on the reliability of Material Safety Data Sheets (MSDS) for paint thinner. J. Korean Soc. Occup. Environ. Hyg. 13: 261-272.

Linak, E., Leder, A. and Yoshida, Y. (1992). $C_{2}$ chlorinated solvents. In Chemical economics handbook. SRI International, Menlo Park, CA, pp. 632.3000632.3001 .

ME (2012). Clean air pollution act enforcement rules. Asterisk 33. Automotive fuel, additives or manufacturing of catalyst. Ordinance of the Ministry of Environment No.463, 1.

MOEL (2013). Standards on the classification, labeling and material safety data sheets of chemicals. Ministry of Labor Public Notice No. 2013-37, 8.

MOEL (2016). Exposure criteria for chemical and physical agents. Ministry of Employment and Labor Public Notice No. 2016-41.

OSHRI (2012). Casebook diagnosis of occupational diseases-2011. Occupational Safety and Health Research Institute, Korea.

OSHRI (2013). Epidemiological survey report for determination of an occupational disease case. Occupational Safety and Health Research Institute, Korea.
Paik, N.W., Yoon, C.S., Zoh, K.E. and Jung, H.M. (1998). A study on composition of thinners used in Korea. $J$. Korean Soc. Occup. Environ. Hyg. 8: 105-114.

Park, D., Stewart, P.A. and Coble, J.B. (2009). A comprehensive review of the literature on exposure to metalworking fluids. J. Occup. Environ. Hyg. 6: 530 541.

Ro, D.S. (1975). A Study on threshold limit value of atmospheric environment for thinner-handling workers in Korea. J. Korea Univ. Med. School 12: 183-193.

Roh, Y.M., Kwon, G.B., Park, S.H. and Jeong, J.Y. (2001). A survey on the management of chemical substances and airborne concentration in laundries exposed to organic solvents. J. Korean Soc. Occup. Environ. Hyg. 11: 70-77.

Seixas, N.S., Robins, T.G. and Moulton, I.H. (1988). The use of geometric and arithmetic mean exposures in occupational epidemiology. Am. J. Ind. Med. 14: 465477.

Sheen, D.H. (2001). Trends of qualities of gasoline and diesel fuels. Fuel Lubr. Automot. Engines 23: 13-19.

Shin, K.A. (1995). Qualitative analysis and quantification of VOCs in ambient air at gasoline service stations and roadsides. Master's Thesis, Graduate School Seoul City University, Korea.

Song, S.H., Paik, N.W. and Ha, K.C. (2000). A study on exposure to volatile organic compounds at gas station in Korea. J. Korean Soc. Occup. Environ. Hyg. 10: 58-73.

Tsai, J.H., Yao, Y.C., Huang, P.S. and Chiang, H.L. (2017). Criteria pollutants and volatile organic compounds emitted from motorcycle exhaust under various regulation phases. Aerosol Air Qual. Res. 17: 1214-1223.

Williams, P., Panko, J., Unice, K., Brown, J. and Paustenbach, D. (2008). Occupational exposures associated with petroleum-derived products containing trace levels of benzene. J. Occup. Environ. Hyg. 5: 565-574.

Yao, Y.C., Tsai, J.H., Wang, I.T. and Tsai, H.R. (2017). Investigating criteria and organic air pollutant emissions from motorcycles by using various ethanol-gasoline blends. Aerosol Air Qual. Res. 17: 167-175.

Received for review, August 18, 2018 Revised, November 25, 2018 Accepted, November 25, 2018 